\title{
Chronic Achilles Tendon Rupture Reconstruction Using the Lindholm Method and the Vulpius Method
}

\author{
Firat Ozan ${ }^{\mathrm{a}, \mathrm{d}}$, Fatih Dogar ${ }^{\mathrm{b}}, \mathrm{Kaan}_{\mathrm{G}}$ Gurbuz $^{\mathrm{a}}$, Yakup Ekinci ${ }^{\mathrm{a}}$, Semmi Koyuncu ${ }^{\mathrm{c}}$, \\ Hazim Sekban ${ }^{\text {a }}$
}

\begin{abstract}
Background: We investigated the clinical and functional outcomes of chronic Achilles tendon rupture reconstruction via the Lindholm technique and via the Vulpius' lengthening of the gastrocnemius.

Methods: We evaluated 15 patients with chronic Achilles tendon rupture (Lindholm technique in eight patients and primary repair with the Vulpius technique in seven patients). In the final follow-up, the Hooker scale was used to measure the ankle functional capacity in all patients. The patients were evaluated on the basis of their capability to stand on tiptoe on the affected limb and the time required to return to pre-injury daily activities.
\end{abstract}

Results: The mean follow-up time was 19.6 months (range, 12 38 months). The mean time to return to work and daily activity was 3.2 months. The mean calf atrophy at the end of follow-up was $1.2 \mathrm{~cm}$ (range, $0-2.5 \mathrm{~cm}$ ). At the last follow-up visit, no patient had any limitation in the activities of daily living and the active and passive ankle range of motion was good. All patients were able to perform single-leg heel rises at the end of follow-up and the Hooker scores were excellent for 11 patients and satisfactory for four patients.

Conclusion: The reconstruction of chronic Achilles tendon ruptures via the Lindholm technique or via the Vulpius technique is associated with good clinical and functional outcomes.

Keywords: Achilles tendon rupture; Chronic rupture; Lindholm technique; Vulpius technique

Manuscript accepted for publication April 24, 2017

aDepartment of Orthopedics and Traumatology, Kayseri Training and Research Hospital, Kayseri, Turkey

${ }^{b}$ Department of Orthopedics and Traumatology, Necip Fazil State Hospital, Kahramanmaras, Turkey

${ }^{\mathrm{c}}$ Department of Orthopedics and Traumatology, Bayburt State Hospital, Bayburt, Turkey

${ }^{\mathrm{d} C o r r e s p o n d i n g ~ A u t h o t: ~ F i r a t ~ O z a n, ~ D e p a r t m e n t ~ o f ~ O r t h o p e d i c s ~ a n d ~ T r a u m a-~}$ tology, Kayseri Training and Research Hospital, Sanayi Mah. Ataturk Bulvari, Hastane Cad. 38010 Kocasinan, Kayseri, Turkey.

Email: firatozan9@gmail.com

doi: https://doi.org/10.14740/jocmr2943w

\section{Introduction}

The Achilles tendon is one of the most commonly ruptured tendons in the body, typically affecting patients between 35 and 60 years old [1-3]. Achilles tendon ruptures usually are more common in men than in women and occur mostly during sports activities [1-4]. Patients typically experience sudden sharp pain and/or a feeling of shot pain behind the leg at injury $[1,4]$. Although clinical examination is sufficient to diagnose Achilles tendon rupture after injury, approximately 10-25\% of complete acute ruptures are missed initially and diagnosed later $[2,5,6]$.

The optimal treatment of chronic Achilles tendon rupture is surgical repair $[5,6]$ and various techniques have been described $[3,6,7]$. It is difficult to treat a chronically ruptured Achilles tendon because there usually is a gap between the ends of the tendon, scarring, retraction of calf muscles and loss of contractility of the triceps surae $[3,5,8]$. These problems make the treatment of chronic Achilles tendon ruptures different from that of acute ruptures $[5,8,9]$.

Operative techniques to repair chronic Achilles ruptures include primary repair and augmentation with fascia advancement, tendon transfer, free tissue transfer, synthetic grafts or allografts $[2,3,5-8,10,11]$. Some techniques have been combined, such as primary repair and Vulpius' lengthening of the gastrocnemius $[3,6]$. The Lindholm method is a technique in which double flaps from the gastrocnemius aponeurosis are used for the Achilles reconstruction [12].

We investigated the clinical and functional outcomes of chronic Achilles tendon rupture reconstruction via the Lindholm technique and primary repair via the Vulpius' lengthening of the gastrocnemius.

\section{Materials and Methods}

We retrospectively analyzed 15 patients (13 males, two females; 10 right, five left; mean age, 35.2 years; range, 22 42 years) who underwent two different surgical techniques (Lindholm technique in eight and primary repair with Vulpius technique in seven) for chronic Achilles tendon rupture repair between 2010 and 2015 (Fig. 1). The characteristics of the patients are presented in Table 1.

For all the patients, at least 4 weeks had passed since the 
a
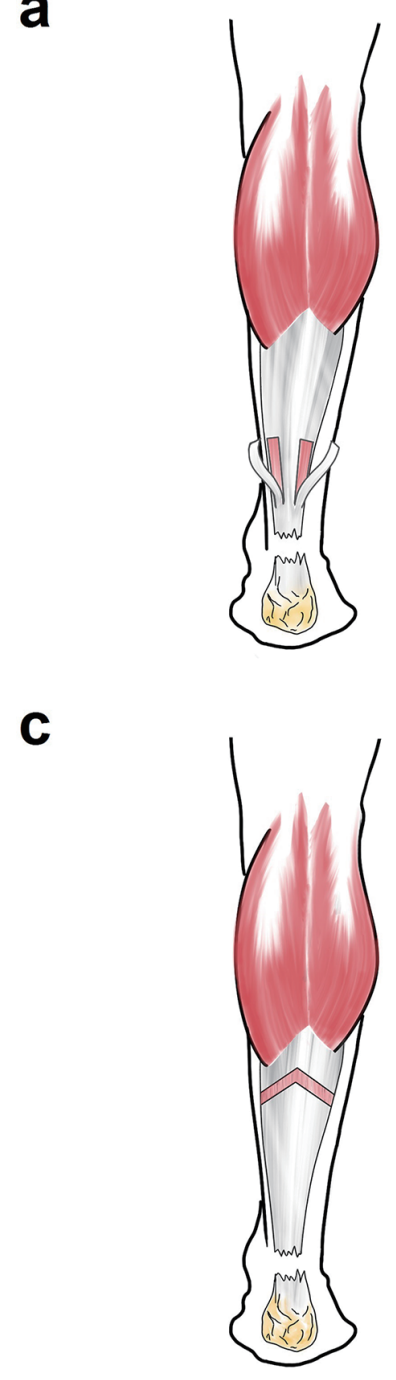

b
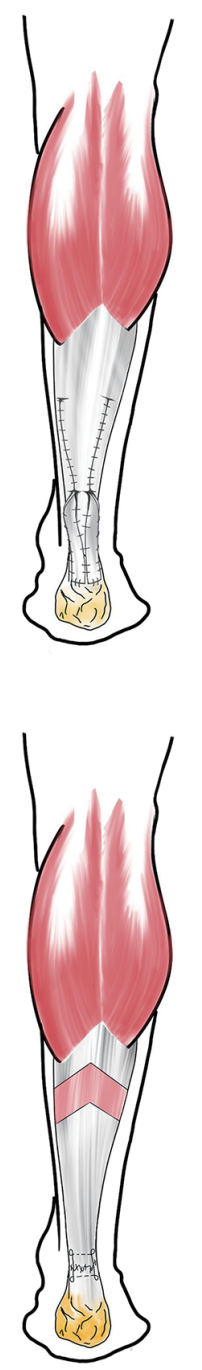

Figure 1. Schematic illustration of the Lindholm technique $(a, b)$ and primary repair with Vulpius' lengthening of the gastrocnemius (c, d).

primary injury. All patients were diagnosed by physical examination and magnetic resonance imaging (MRI). The chief complaints included significant disability and weakness in performing activities of daily living and limping. On physical examination, there was a gap at the site of the ruptured tendon and the calf squeeze test was positive in all patients. None of them could stand on tiptoe.

\section{Surgical technique}

The surgical procedure was performed with the patient prone under spinal or general anesthesia. Initially, a longitudinal posterior midline incision was made. The Achilles tendon was exposed and the ruptured ends are debrided. Then, the length of the tendon defect was measured with the ankle plantarflexed up to $20^{\circ}$, and surgical reconstruction methods were performed.
In the Lindholm technique, the transfer of the two split fascia from the sides of the gastrocnemius coupled with the suturing of the ruptured area after a $180^{\circ}$ turn was performed (Fig. 2).

In the Vulpius technique, a "V" incision was performed in the proximal gastrocnemius with its apex proximal. The arms of the "V" were approximately $10 \mathrm{~cm}$ in length or about one and half times the length of the defect, to allow for sufficient lengthening. Next, the proximal stump of the Achilles tendon was pulled distally until it can bridge the gap with the foot held in plantar flexion. Then, anastomosis was sutured with nonabsorbable material by the modified Kessler method (Fig. 3).

Postoperatively, a short-leg splint was applied to the ankle joint with the plantarflexion at $20^{\circ}$. The cast was generally applied for 4 weeks, but it was used for up to 6 weeks in patients where the state of the remaining tendons was poor. Then, the patients were allowed to bear weight as tolerated after removed the cast and physical therapy was initiated. Active 
Table 1. Patient Characteristics

\begin{tabular}{|c|c|c|c|c|c|c|c|c|c|}
\hline Patients & Sex & Age & Side & $\begin{array}{l}\text { Gap } \\
(\mathrm{cm})\end{array}$ & $\begin{array}{l}\text { Cause of } \\
\text { injury }\end{array}$ & $\begin{array}{l}\text { Time between injury } \\
\text { and surgery (day) }\end{array}$ & $\begin{array}{l}\text { Follow-up } \\
\text { (months) }\end{array}$ & $\begin{array}{l}\text { Immobilized } \\
\text { (week) }\end{array}$ & Surgical technique \\
\hline 1 & M & 28 & $\mathrm{~L}$ & 6 & Football & 40 & 12 & 3 & Primary repair + Vulpius \\
\hline 2 & M & 39 & $\mathrm{R}$ & 3 & Football & 30 & 18 & 4 & Primary repair + Vulpius \\
\hline 3 & M & 38 & $\mathrm{R}$ & 4 & Football & 30 & 14 & 5 & Primary repair + Vulpius \\
\hline 4 & M & 28 & $\mathrm{R}$ & 4 & Football & 45 & 15 & 5 & Primary repair + Vulpius \\
\hline 5 & M & 42 & $\mathrm{~L}$ & 3 & Football & 35 & 21 & 5 & Primary repair + Vulpius \\
\hline 7 & M & 39 & $\mathrm{~L}$ & 3 & Football & 35 & 20 & 4 & Primary repair + Vulpius \\
\hline 8 & M & 32 & $\mathrm{~L}$ & 4 & Football & 60 & 24 & 3 & Lindholm \\
\hline 9 & M & 39 & $\mathrm{R}$ & 4 & Football & 45 & 18 & 5 & Lindholm \\
\hline 10 & M & 41 & $\mathrm{R}$ & 4 & Football & 60 & 17 & 5 & Lindholm \\
\hline 14 & $\mathrm{~F}$ & 22 & $\mathrm{~L}$ & 4 & Fall & 30 & 24 & 3 & Lindholm \\
\hline 15 & M & 38 & $\mathrm{R}$ & 4 & Football & 35 & 38 & 3 & Lindholm \\
\hline
\end{tabular}

joint exercises were started, and other muscle-strengthening exercises, such as cycling, passive joint exercise, stretching and heel rises, were gradually performed as comfort allowed.

In the final follow-up, the Hooker scale [13] (Table 2) was used to measure the ankle functional capacity in all patients. Ankle range of motion (plantar flexion and dorsiflexion) was measured using a goniometer. The patients were investigated regarding their capability to stand on tiptoe on the affected limb and the time required to return to pre-injury daily activities. The study was approved by our Institutional Review Board, and all patients provided informed consent.

\section{Results}

The clinical and functional outcomes of the patients are presented in Table 3. The mean follow-up was 19.6 months (range, 12 - 38 months), the mean interval between injury and surgi- cal reconstruction was 42 days (range, 30 - 60 days) and the mean ruptured gap was $4 \mathrm{~cm}$ (range, $3-6 \mathrm{~cm}$ ). The mean calf atrophy was $1.2 \mathrm{~cm}$ (range, $0-2.5 \mathrm{~cm}$ ) at the end of follow-up. The mean time for patients to return to daily activity was 3.2 months (range, 2 - 5 months).

No patient had any limitation in the activities of daily living. The active and passive ankle range of motion was good. No patient could perform affected-side heel rise preoperatively, but all patients were able to do so at the end of follow-up. The Hooker scores were excellent for 11 patients and satisfactory for four patients. All tendons healed without complications. No infections, nerve injuries, or re-ruptures occurred inter- or postoperatively.

\section{Discussion}

In our study, at a midterm follow-up (mean, 19 months), re-
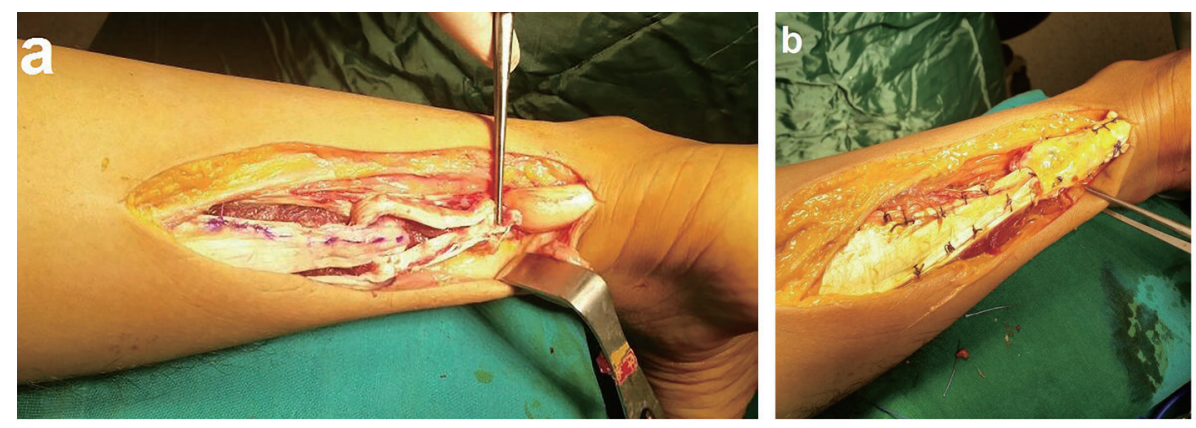

Figure 2. Intraoperative view of the Lindholm technique application. (a) Reconstruction of Achilles rupture defect with medial and lateral flaps harvested from the gastrocnemius. (b) Final view of the reconstruction after augmentation of the plantaris longus tendon. 

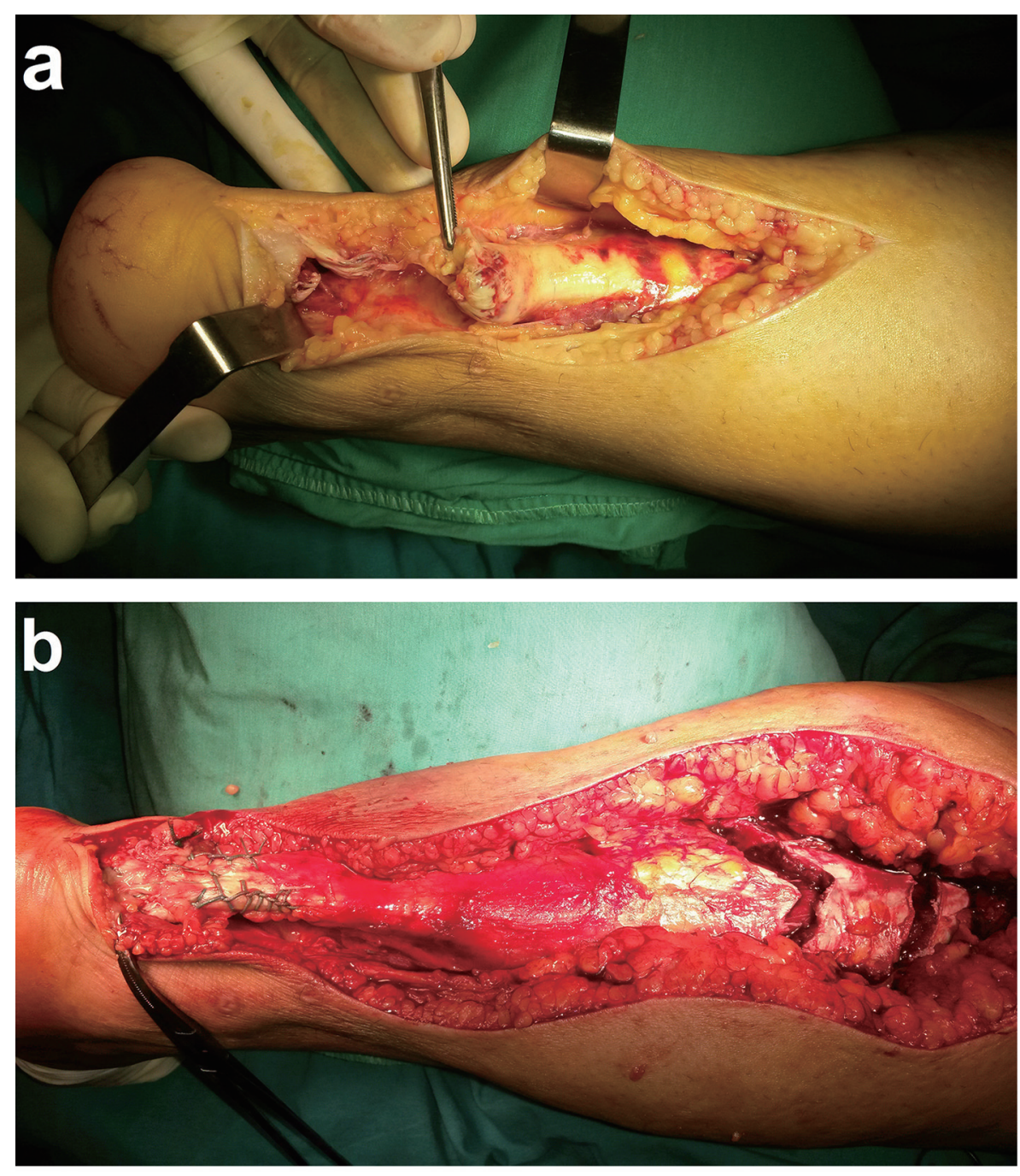

Figure 3. Intraoperative view of the Vulpius technique application. (a) The view of the gap at the chronically ruptured Achilles tendon. (b) The final view of the primary repair of the defect after lengthening of the gastrocnemius via a reverse $\mathrm{V}$ shape.

construction of the chronic Achilles tendon ruptures via the Lindholm technique and primary repair with Vulpius' method provided tendon healing and good clinical and functional outcomes. All of our patients had returned to their pre-injury daily activity level in 3 months. There was no functional deficit and the results were satisfactory in all patients.

Many surgical procedures have been described for reconstruction of the chronic Achilles tendon rupture, each with some advantages and disadvantages $[2,3,5-8,10]$. In addition, despite many repair techniques having been described, there is no evidence-based guideline for deciding on the type of operative management for neglected Achilles ruptures [14, 15].
The gap between the tendon ends could not be closed with proper tension in the chronic Achilles tendon rupture. This can be achieved only by interposition of the gastrocnemius fascia with a central flap or double (medial and lateral) flaps in between the tendon ends $[12,16]$. In addition, the plantaris longus tendon could be used as a supportive membrane. In all of our cases, the plantaris longus tendon was augmented to the tear area of the Achilles tendon.

In the Lindholm [12] surgical technique, two flaps harvested from the gastrocnemius facia and flat surfaces facing the skin are used by turning them $180^{\circ}$ and, thus, preventing tendon adhesions. Hosey et al [17] reported satisfactory results

Table 2. The Hooker Assessment Scale

\begin{tabular}{lll}
\hline Excellent & Satisfactory & Poor \\
$\begin{array}{l}\text { None of patients } \\
\text { had symptoms }\end{array}$ & $\begin{array}{l}\text { Patients were free from symptoms but there } \\
\text { was weakness of the calf detected or excessive } \\
\text { passive dorsiflexion of the ankle. }\end{array}$ & $\begin{array}{l}\text { In addition to the findings of satisfactory, the } \\
\text { patients experienced symptoms either of weakness } \\
\text { of the ankle or foot or of a limp or pain. }\end{array}$ \\
\hline
\end{tabular}


Table 3. Clinical Outcomes of Patients

\begin{tabular}{|c|c|c|c|c|c|c|c|}
\hline Patients & $\begin{array}{l}\text { Returned to pre-injury } \\
\text { daily activities (months) }\end{array}$ & $\begin{array}{l}\text { Stand on } \\
\text { tiptoe }\end{array}$ & $\begin{array}{l}\text { Plantar } \\
\text { flexion }\left({ }^{\circ}\right)\end{array}$ & $\begin{array}{l}\text { Dorsiflexion } \\
\left({ }^{\circ}\right)\end{array}$ & $\begin{array}{l}\text { Calf atrophy } \\
(\mathrm{cm})\end{array}$ & $\begin{array}{l}\text { Satisfaction (Hooker } \\
\text { classification) }\end{array}$ & Complication \\
\hline 1 & 2 & Normal & 40 & 15 & 0 & Excellent & No \\
\hline 3 & 2 & Normal & 32 & 25 & 2 & Excellent & No \\
\hline 4 & 5 & Normal & 35 & 24 & 2 & Excellent & No \\
\hline 7 & 4 & Normal & 35 & 20 & 0 & Excellent & No \\
\hline 8 & 3 & Normal & 40 & 20 & 0 & Excellent & No \\
\hline 9 & 3 & Normal & 40 & 20 & 1 & Excellent & No \\
\hline 10 & 3.5 & Normal & 40 & 15 & 2 & Excellent & No \\
\hline 14 & 2 & Normal & 45 & 20 & 1 & Satisfactory & No \\
\hline 15 & 3 & Normal & 40 & 15 & 2 & Excellent & No \\
\hline
\end{tabular}

using a modified Lindholm technique; however, none of their patients returned to their full preoperative athletic capabilities.

In other techniques, semitendinosus, flexor hallucis longus, tibialis posterior and peroneus brevis tendons have been used as free or pediculated transposition flaps $[2,5,6,18,19]$. Wapner et al [19] reported good functional results after the dynamic repair of chronic Achilles tendon ruptures with flexor hallucis longus tendons.

Simultaneously, good clinical results have been reported in chronic Achilles tendon ruptures reconstructed with synthetic materials and Achilles tendon allografts; however, these studies are limited in the literature $[6,8,11,18]$. Although using Achilles allografts to reconstruct the chronic Achilles tendon ruptures provides surgical flexibility and convenience, the disadvantages may include rejection of the allograft, spread of infectious diseases and deep infection $[6,8,11,18]$.

Reconstruction of the chronically ruptured Achilles tendon may have some complications [5], such as adhesions, wound breakdown and infection $[2,5,10]$. Tendon adhesions are encountered more frequently in patients who had conservative treatment than in those who underwent reconstructive surgery, and a $2.6-45 \%$ complication rate has been reported [20]. In our study, we did not encounter any major complication (deep vein thrombosis, re-rupture and deep infections) or minor complication (hematoma and superficial wound infection).

Our study was limited by the small patient population because chronic Achilles tendon rupture is rare. In addition, we did not evaluate the strength of the plantar flexion of the affected foot compared to the normal side. Another limitation of our study is that surgical procedures were performed by multiple surgeons.

In conclusion, based on the findings of the current study, we recommend reconstruction of the chronic Achilles tendon ruptures via the Lindholm technique or primary repair with the Vulpius technique. Both are associated with good clinical and functional outcomes.

\section{Competing Interests}

The authors declare that they have no competing interests.

\section{Grant Support}

None.

\section{Financial Disclosure}

None.

\section{References}

1. Leslie HD, Edwards WH. Neglected ruptures of the Achilles tendon. Foot Ankle Clin. 2005;10(2):357-370.

2. Yeoman TF, Brown MJ, Pillai A. Early post-operative results of neglected tendo-Achilles rupture reconstruction using short flexor hallucis longus tendon transfer: a prospective review. Foot (Edinb). 2012;22(3):219-223.

3. Us AK, Bilgin SS, Aydin T, Mergen E. Repair of neglected Achilles tendon ruptures: procedures and functional results. Arch Orthop Trauma Surg. 1997;116(6-7):408411.

4. Surel YB, Zorer G, Caliskan R, Balioglu MB, Karli M. 
Operative treatment of the achill tendon ruptures. Acta Orthop Traumatol Turc. 1995;29(5):32-36.

5. Sarzaeem MM, Lemraski MM, Safdari F. Chronic Achilles tendon rupture reconstruction using a free semitendinosus tendon graft transfer. Knee Surg Sports Traumatol Arthrosc. 2012;20(7):1386-1391.

6. Park YS, Sung KS. Surgical reconstruction of chronic achilles tendon ruptures using various methods. Orthopedics. 2012;35(2):e213-218.

7. Lapidus LJ, Ray BA, Hamberg P. Medial Achilles tendon island flap - a novel technique to treat reruptures and neglected ruptures of the Achilles tendon. Int Orthop. 2012;36(8):1629-1634.

8. Jennings AG, Sefton GK. Chronic rupture of tendo Achillis. Long-term results of operative management using polyester tape. J Bone Joint Surg Br. 2002;84(3):361-363.

9. Lee YS, Lin CC, Chen CN, Chen SH, Liao WY, Huang CR. Reconstruction for neglected Achilles tendon rupture: the modified Bosworth technique. Orthopedics. 2005;28(7):647-650.

10. Maffulli N, Del Buono A, Spiezia F, Maffulli GD, Longo UG, Denaro V. Less-invasive semitendinosus tendon graft augmentation for the reconstruction of chronic tears of the Achilles tendon. Am J Sports Med. 2013;41(4):865871.

11. Lee DK. Achilles tendon repair with acellular tissue graft augmentation in neglected ruptures. J Foot Ankle Surg. 2007;46(6):451-455.

12. Lindholm A. A new method of operation in subcutane- ous rupture of the Achilles tendon. Acta Chir Scand. 1959; 117:261-270.

13. Hooker CH. Rupture of the tendo calcaneus. J Bone Joint Surg. 1963;45:360-363.

14. Maffulli N, Ajis A. Management of chronic ruptures of the Achilles tendon. J Bone Joint Surg Am. 2008;90(6):13481360.

15. Hadi M, Young J, Cooper L, Costa M, Maffulli N. Surgical management of chronic ruptures of the Achilles tendon remains unclear: a systematic review of the management options. Br Med Bull. 2013;108:95-114.

16. Bosworth DM. Repair of defects in the tendo achillis. J Bone Joint Surg Am. 1956;38-A(1):111-114.

17. Hosey T, Wertheimer S. A retrospective study on surgical repair of the Achilles tendon. J Foot Surg. 1984;23(2):112$115,184$.

18. Kocabey Y, Nyland J, Nawab A, Caborn D. Reconstruction of neglected Achilles' tendon defect with peroneus brevis tendon allograft: a case report. J Foot Ankle Surg. 2006;45(1):42-46.

19. Wapner KL, Pavlock GS, Hecht PJ, Naselli F, Walther R. Repair of chronic Achilles tendon rupture with flexor hallucis longus tendon transfer. Foot Ankle. 1993;14(8):443449.

20. Cetti R, Christensen SE, Ejsted R, Jensen NM, Jorgensen U. Operative versus nonoperative treatment of Achilles tendon rupture. A prospective randomized study and review of the literature. Am J Sports Med. 1993;21(6):791799. 